\title{
QALYs: are they enough? A health economist's perspective
}

\author{
Gavin Mooney University of Copenhagen, Denmark
}

\section{Author's abstract}

Fohn Rawles's criticism of QALYs are seen as being both imprecise and largely unhelpful.

This paper accepts that there are problems in both QALYs themselves and in the current decision-making processes with which they seek to help. The QALY pliers tend to play down the former and the QALY knockers the latter.

It is suggested that theories (regret theory and prospect theory) other than expected utility theory, which is normally seen as the basis for QALYs, may provide better approaches to measuring health service outputs. Thus equity, information and decision-making per se are not handled as well in the expected utility QALYs as they could be. Developing better $Q A L Y s$, with qualifications, is the goal.

\section{Introduction}

Measuring health outputs is important - unless one is from those schools of thought that argue that it is not possible to measure health status, that it is just constructing castles on sand' (1); or that it is dangerous to do so (2). This paper accepts the importance of attempting to measure QALYs - quality adjusted life years - but questions whether they are adequate in measuring all that we would wish to measure in the interest of both health service goals and individual patient welfare.

To that extent the paper represents both a defence and a critique of some aspects of QALYs. However, it does not join John Rawles (3) (in this issue of JME) in 'castigating QALYs'. Since at least some of his criticisms are none the less relevant to my defence in principle of QALYs, I have discussed these in the next section of this paper.

The underlying premise of my paper is that QALYs per se do not create any ethical problems (or at least do not add to existing ones) in health care decisionmaking. However, they may if it is assumed that 'maximising QALYs' can embrace the equity goals of health care and if health is assumed to be the only output of health services.

The paper beyond this introduction is in four parts. Section 2 castigates Rawles. Some theoretical issues surrounding utility are considered in Section 3 . Section
4 discusses the relationship of QALY maximisation to health service objectives. Finally there is a brief conclusion.

There are various issues related to QALYs that are not raised in this paper. Most important of the omissions is the handling of risk and uncertainty. Much of the literature on QALYs assumes that the relevant decision-makers are risk-neutral (ie expected utility is equal to the 'objective' probability that a particular health state will occur multiplied by the utility associated with that health state). This somewhat questionable and important assumption is not dealt with here.

\section{Castigating Rawles}

Rawles is so indiscriminately critical of QALYs that it is difficult to see what his fundamental objections are. Here I want to discuss some possibilities.

(i) QALYs attempt to measure the immeasurable. That does not seem to be the objection - since he is concerned that life is relatively undervalued by QALYs vis-a-vis suffering which implies at least that he accepts that quantity and quality of life can be weighed against each other.

(ii) QALYs use values with which he disagrees. That certainly seems to be one of his objections against the Kind et al (4) QALYs (but note that there are other QALYs: see for example the work of Torrance (5) at McMaster). But this is hardly a fundamental objection. Indeed one of the advantages of developing QALYs is that the underlying values used are made explicit and consequently can be debated.

(iii) Doctors' opinions 'may well be right'. Yes they may be but it would only be if they always were that the need for QALYs would be removed in clinical decision-making. And Rawles does not attempt to claim that. Further, presumably Rawles would agree that doctors' opinions should not be the basis of health services policy, so the issue does not arise there.

(iv) Management by Shroud Waving (MSW) may well be right. John Rawles is in favour of MSW where individual clinicians press for more resources for their 
patients by 'announcing publicly that unless resources are increased patients will suffer and die unnecessarily'. Each individual clinician 'has, after all, spent his professional life assessing his patients' distress and disability and the risk to their lives posed by disease'.

If John Rawles wishes to support resource allocation and priority setting by MSW then of course he is entitled to that opinion. But there are four things I would mention about MSW as a basis for the rational allocation of society's scarce resources in health care.

(a) They are society's resources that are used in health care. It is not clear - but maybe we should find out that society has delegated this task of priority setting to the doctors.

(b) MSW is unlikely to be equitable unless somehow all clinicians are equally skilled in it and are able to reflect social preferences and not just their own or their patients.

(c) MSW is not a formal part of medical undergraduate education. If it is to be the basis for determining priorities in health care, ought it not to be recognised as a part of the curriculum? If we are to have MSW, let's at least have clinicians well trained in it.

(d) MSW does not require QALYs or any other explicit measure of output, or of costs. It requires the clinician to attract as many resources for his/her patients as he/she can but apparently according to Rawles without stating explicitly what benefit in terms of improved health status will arise and without taking account of the fact that these extra resources might have produced greater benefit elsewhere.

Rawles may be right to imply that MSW may sometimes get it right. But is it a defensible way to allocate our health care resources?

(v) Facing up to improving efficiency with the resources available is a less worthwhile goal than pressing for more resources.

Rawles may be right on this, although proving it one way or the other would seem difficult. Certainly attempting to treat people's needs irrespective of the relative cost of treatment is a comforting dictum, at least for the treaters. But insofar as one of the goals of the health service is about comfort, it is the comfort of the patients and not the doctors. And Rawles's dictum is not comforting for patients.

Let us take a simple example. Assume that 100 lives can be saved by each of five different treatments, $A$ to E. A costs $£ 10,000, B £ 20,000, C £ 30,000, D £ 40,000$ and $E £ 50,000$. Now if we select 100 lives to save randomly - the Rawles approach - then the expected cost will be $£ 3$ million ( 20 of each of $A, B, C, D$ and $E$ being equal to $£ 200,000+£ 400,000+£ 600,000+\underset{+}{ \pm}$ $£ 800,000+£ 1,000,000$ ). People are thus not $\overrightarrow{\overline{\bar{T}}}$. 'penalised' because they have expensive illnesses, nor? favoured because their problems are cheap to treat. $\vec{\Rightarrow}$

But we could save 200 lives for $£ 3 \mathrm{~m}$ ie 100 of $\mathrm{A}$ and $\stackrel{\text { ? }}{?}$ 100 of B or we could save 100 lives (A lives) for $£ 1 \mathrm{~m}$ and $\overline{\mathrm{C}}$ have $£ 2 \mathrm{~m}$ 'savings' for reducing suffering elsewhere. $\frac{\overline{\bar{N}}}{\bar{N}}$

This Rawles's theory of justice is expensive in terms $\vec{\sigma}$ of death and suffering. He places a very high weight on $\triangle$ equity. There is frequently a conflict between equityo and efficiency and that means that some trade-off is $\vec{\circ}$ then necessary. Whether the Rawles's weight on equityis too great is open to debate.

However, the economist's approach at least then? poses the question: are you John Rawles prepared to sacrifice 100 lives in the cause of justice? Economists cannot or at least should not qua economists attempt to $\sigma_{\omega}^{\mathcal{T}}$ answer such a question ( I am not even sure that it is for $-\overrightarrow{-}$ clinicians to answer it) but they would argue that it is 0 advantageous to pose it. Similarly when Rawles wants음 'prolongation of life' to have 'overriding priority'economists with their QALYs simply want to ask him $\Phi$ to quantify 'overriding'.

It is not clear why Rawles objects to QALYs. $\frac{\mathbb{D}}{3}$ Certainly his paper does not provide evidence for the concluding comment that 'distributing health care according to value for money, assessing outcome os $\overrightarrow{0}$ Quality Adjusted Life Years, is based on fatsec. premises, faulty reasoning and unjust principles'.

However, there are some problems with QAL which should get us to think about how best health care outputs can be measured. That is the real challengen that QALYs present and which I now want to turn too in the rest of this paper.

\section{Some fundamentals}

\subsection{Some (possible) problems?}

While it can be difficult to be uncontentious in this area, there would seem to be general agreement that whatever QALYs do do, they do not in principle nor inopractice 'solve' the problem of interpersona?. comparisons of utility. Rather they accept that the tasko of decision-making about diagnostic and therapeutic choices and about health care policy-making involveso interpersonal comparisons of utility anyway and that such choices are better made as explicitly and aso. informedly as possible. As Dowie states (6):

'The QALY is fundamentally a symbol of the intention to tackle this horrifying task in an analytically expliciț fashion and quantitatively, rather than covertly qualitatively and ... intuitively'.

Distributionally the assumption frequently made is that Jensen's QALY is equal to Nielsen's QALY. Thato can however readily be adjusted by some agreedo् weighting system (other than unitary weights). What is less clear here is two things: whose preferences shouldo count in determining weights for different socia ${ }_{-}$ groupings; and what weight should be attached to 
different individuals' preferences. For example, it might be agreed that only adults' preferences should count but then should all adults' preferences count equally - and who decides that? Beyond that issue it may not be too difficult to agree on weights between rich and poor; young and old; male and female. Where other types of difficulties may arise however is in relation to the possibility that there may be nonconstant marginal utility of health. In other words, are 2 extra QALYs to Jensen equal to twice 1 extra QALY to Jensen? Again, in practice, this can be handled by devising appropriate empirical weights.

The implicit assumption built into QALYs appears to be (this is more contentious) that it is only outcomes that matter and there is no utility attached to process (for example the decision-making process). For example, Dowie (6) states: 'QALYs ... assume the only relevant utilities produced from procedures are outcome-based. So that the "process" involved in the procedure isn't regarded as in itself generating utility or disutility'.

Further and perhaps still more contentious, QALYs are normally based on expected utility theory. Explicitly, this means that it is the utilities associated with the consequences of the described states of the world that are deemed relevant. In other words and inter alia the utility associated with health state $\mathrm{H}_{\mathrm{n}}$, is independent of $\mathrm{H}_{\mathrm{i}}$, the health state one is in when the judgement is made. Further when the question of choice is explicitly considered and there is a range of possible outcomes, with various attached probabilities, then the state(s) of the world not chosen do not affect the utility obtained from the state of the world attained. Translated into health status or QALY terms, these considerations mean that

(i) only health status is relevant;

(ii) the utility of an expected or possible health state is independent of current health state (and at least in some forms - see Kind, Rosser and Williams (4) independent of future expected health state ie prognosis);

(iii) related to (ii) nominally equal changes in health state are valued equally whether they are gains or losses, except for the sign;

(iv) the utility associated with the health states possible but not selected does not enter the consumer's/patient's (doctor agent's?) utility function.

\subsection{Some (possible) solutions?}

The above comments are not arguments against measuring health outputs. I am in favour of measuring health outputs. Rather I am contending that insofar as QALYs are built on expected utility theory they may suffer from certain weaknesses. There are other possible theories here that merit investigation such as regret theory (see Loomes and Sugden, (7)) and prospect theory (see Kahneman and Tversky, (8)).
Space does not allow detailed consideration of these theories here. However, it is relevant to give a flavour of what they involve. Regret theory for example allows disutility because the individual knows (ex post) that he/she could have had a better outcome. Prospect theory focusses on change thereby allowing current health status to influence valuations of other health states. (An individual may value the state of blindness in both eyes differently depending on whether that person has the sight of two eyes now or of only one eye now.)

There are potential advantages in these approaches. That is not so important in itself. Rather it suggests that there is a need for research on QALYs at least to recognise the existence of these other theories and to consider their relative merits.

\section{QALYs: Is there anything else there?}

\subsection{Equity}

One of the key issues surrounding QALYs has not been much discussed in the literature associated with QALYs. That is: what are the arguments in health care consumers' utility functions and, related, what are the arguments in the health care social welfare function?

Here I do not want to consider these issues at large. Rather I simply want to place a question mark over the assertion sometimes made that health services are about health and only that. It is an important issue. If they are only about health and even more so if they are only about health maximisation, subject to some budget/resource constraint, then the QALY pliers may be right to argue that priorities in health care should be determined on the basis of cost per QALY on the margin. If they are also about something in addition to health per se then that does not necessarily negate the QALY approach. It simply means, and I believe importantly, that the decision rule of priority setting according only to cost per QALY on the margin may not be adequate to ensure efficiency objectives and/or equity objectives.

This issue is more important than I had hitherto thought because at least some QALY pliers argue that issues of efficiency can be contained wholly within QALYs and, further, that maximising QALYs embraces equity.

In a recent paper, Culyer (9) discusses inequality in health care. In an explicit effort to limit the arena for debate Culyer states that he will assume that 'there are no differences between people as to what health services are for'. He continues that for his purposes 'there is plainly an advantage... in choosing an objective [for health care] that is - so far as one can judge these things - likely to command a consensus, which is not particularly quirky nor merely the idiosyncratic view of a particular pressure group or the tenet of a major but controversial political and social ideology'. He states: 'The objective that will be assumed here to command a consensus is based on the proposition that health services exist to promote health'. $\mathrm{He}$ then restates the objective as: 'given the resources 
available to the health services, the health of the community should be maximised'.

Culyer's defence of this position is that 'If equality is to be defended it is because its results are good; if attacked because they are bad'. This is a wholly consequentialist position where Culyer has already stated that the only consequences that are relevant relate to health.

Elsewhere, assuming that it has been possible to embody all the relevant weights - (for age, desert, important social position, etc) to be placed on $Q A L Y s$ (my emphasis) - Culyer (10) then asks rhetorically: 'Is there any distributional concern left that has not been embodied?' But it is not necessarily a rhetorical question and indeed the answer may well be yes if objectives of health care go beyond health maximisation or are concerned with arguments beyond health in either individuals' utility functions or society's health care welfare function. It is thus not the assumption about the consensus about objectives that is crucial to Culyer's argument, it is the elimination of non-health status variables (such as, for example, access).

Culyer further suggests, in an attack on equality defined by him (normally) as equality of provision per head, that 'the equality argument is really masquerading as an efficiency argument...' on the basis that, for example, the marginal pay-off in terms of health per pound is greater among the poor than the rich.

There is some doubtful logic here. First, I know of no country which has as its stated equity policy in health care the objective of equality of provision per head; and know of no 'egalitarians' (Culyer's terminology) who advocate such an equity objective. Second, the fact that the marginal pay-off in terms of health per pound for the poor is higher than for the rich does not lead to any masquerading. Of course, I can agree that spending on the poor rather than the rich may be efficient and may lead to overall greater health but I can still support some concept of equity over and above that.

Culyer's claim that 'egalitarianism equals national health maximising' is only tenable if (and there are other, less relevant, conditions here) it is accepted that health care is only about health. It seems to be a somewhat circular argument - but it appears to be the one on which the QALY pliers base their arguments that QALYs can adequately embrace equity.

But how best can equity be considered in health care? Is there an alternative to the QALY maximisers? Here I want to extend a theory advocated by Margolis (11) and which I have addressed at greater length elsewhere (Mooney, (12)). Margolis postulates the idea of self-interested man and group-interested man within the same individual, ie each individual has two (internal) utility functions between which he allocates his resources. One is concerned with purely selfish utility (S-utility) which is a conventional utility function in that the individual derives utility from the spending on his own private goals. The other (GT utility) is concerned with utility derived from contributing to or participating in some group activity, ie is a form of process utility with utility gained from $\overrightarrow{5}$ the process of participation. The individual allocates his resources between these two utility functions in such a way as to maximise his utility. The distinctive contribution of the theory relates to the definition of utility such that the individual derives satisfaction from participating - from doing his fair share.

There are features of the provision of health care $-\overrightarrow{0}$ uncertainty, irrationality, unpredictability, ignorance, externalities - which make it a particularly strong $\vec{\rho}$ candidate for group interest.

Regarding equity, under the 'fair share' approach,, $\overrightarrow{\mathbb{D}}$ the individual seeks to ensure that he is in equilibrium $\vec{G}$ regarding his allocation both selfishly and to the group. $\omega$ He obtains outcome utility in the former, and process $\vec{A}$ utility in the latter. Given that both forms of utility areo0 present and that the group contains the individual as an equal then it is enough for the individual simply to careabout providing access to health care. Whether other ${ }_{\mathbb{D}}^{(s)}$ individuals out of selfish interest then utilise the group $\underset{\mathbb{D}}{-}$ resources is not relevant to the individual. Given ${ }_{3}$ commonality of group interest this will point to equality of access for equal need for members of the group, leaving the selfish interest of differegt $t_{0}^{\circ}$ individuals to determine the value placed on health 1 i $\mathrm{d}^{\circ}$ health care and hence individuals' consumption a thereby health.

One particular advantage of this approach to equity vis-a-vis the QALY pliers is that equality of accesso which is not considered relevant in QALY maximisation is both the dimension of equity emerging $\overrightarrow{\vec{A}}$ from the Margolis model and, importantly, the most common dimension of health care policy statements.

\subsection{QALYs, information and decision-making}

What has been said in the previous sub-section has casto doubt on whether equity can be contained adequately in a welfare function that consists solely of QALYs. But there are other potential utility-bearing characteristics of the commodity health care that may be relevant, particularly at the clinical and individuas patient level. Elsewhere (13) together with others have argued that health is not the only relevant utility‥ bearer in health care.

Additionally health care is about the provision of information and about decision-making. Doctors act ass agents on behalf of patients who lack information about their health status, the availability of treatments and their effectiveness. Patients are generally moreo ignorant about health care than about many othero commodities. As such they may look to the doctor to ${ }^{\circ}$ provide not just treatment which they expect wilए improve their health status (more QALYs) but also information which may have no effect directly on their health status.

It is also the case that patients may seek help from their doctor in the actual decision-making process. The 
uncertainty surrounding health care consumption decisions can be great and patients may welcome the opportunity to pass difficult decision-making to the doctor - even if doing so does not directly affect their health status.

Consequently it would seem that there is a danger that QALYs may be assumed to be all that the output of health care is about. This is open to question. (That, it must be noted, does not make QALYs redundant. Rather it means (a) that they are not enough and (b) that marginal cost per QALY may not be an adequate ranking device in setting priorities in health care.)

What does the evidence show? Is there more than health in health care consumers' utility functions? Studies by Berwick and Weinstein (14) on the value of information in ultrasound and by Strull et al (15) on attitudes of patients to information and decisionmaking would suggest that patients may well wish to have information and decision-making components included in their utility functions.

\section{Conclusion}

Whatever it is that health services are producing is complex. Whatever it is, as an economist, I wish to support the notion of efficiency in its production - the idea of maximising the benefit or utility to society from the resources available subject to the possible constraint of doing so equitably if that is a social goal.

Consequently I support the idea of using QALYs as a mechanism for trying to measure the health outputs of health care. However, I would dispute two things: (i) that maximising QALYs will necessarily embrace equity: it will not - indeed cannot - if the equity goal is couched in terms of equal access; and (ii) that maximising QALYs is the same as maximising utility or benefit since it is my belief that there are other nonhealth outputs that are frequently considered as benefits from the health care system.

QALYs need to be developed, improved. They need to be better understood. Those who prefer to ignore the scarcity of resources and allocate solely on the basis of need, or on the basis of the severity of the problem, or by MSW or by clinical judgement alone will of course be less ready to accept QALYs and more willing to agree with the arguments put forward by John Rawles.

QALYs - with qualifications - is my preferred choice. More important than my preferred choice and more important than John Rawles's preferred choice, however, is the fact (which I think we can all agree on) that how rationally to set priorities in health care is now clearly on the agenda. It is largely the debate about QALYs that has achieved that. Developing QALYs in both principle and practice is now the goal.

\section{Acknowlegement}

The author would like to thank Tony Culyer, Ali McGuire and Erik Nord for comments on an earlier version of this paper, the Forskningsakademi for financial support and Annelise Nielsen for secretarial support.

Gavin Mooney is Professor of Health Economics in the Institute of Social Medicine, University of Copenhagen, Denmark.

\section{References}

(1) Carr-Hill R. QuALitY control: a sensitivity analysis of QALYs. York: Centre for Health Economics, 1988.

(2) Harris J. Qualifying the value of life. Fournal of medical ethics 1987; 13:117-123.

(3) Rawles J. Castigating QALYs. Fournal of medical ethics 1989;

(4) Kind P, Rosser R, Williams A. Valuation of quality of life: some psychometric evidence. In: Jones-Lee $M \mathrm{~W}$, ed. The value of life and safety. Amsterdam: North Holland, 1982.

(5) Torrance G W. Measurement of health state utilities for economic appraisal: a review. Foumal of health economics 1986; 5:1-30.

(6) Dowie J. Professional judgement. Introductory text 8. Milton Keynes: Open University, 1988.

(7) Loomes G, Sugden R. Regret theory: an alternative theory of rational choice under uncertainty. Economic journal 1982; 92:805-824.

(8) Kahneman D, Tversky A. Prospect theory: an analysis of decision under risk. Econometrica 1979; 47:263-291.

(9) Culyer A J. Inequality of health services is, in general, desirable. In: Green D G, ed. Acceptable inequalities? London: IEA, 1988.

(10) Culyer A J. Commodities, characteristics, capabilities, utilities and the quality of life. Paper presented to the IRISS Conference, University of York, 1987 Nov 11-12.

(11) Margolis H. Selfishness, altruism and rationality. Cambridge: Cambridge University Press, 1982.

(12) Mooney G H. Economics, medicine and health care. Brighton: Wheatsheaf, 1986.

(13) McGuire A, Henderson J, Mooney G. The economics of health care. London: Routledge and Kegan Paul, 1988.

(14) Berwick D M, Weinstein M C. What do patients value? Willingness to pay for ultrasound in normal pregnancy. Medical care 1985; 23:881-893.

(15) Strull W M, Lo B, Charles G. Do patients want to participate in medical decision making? Fournal of the American Medical Association 1984; 252, 21:2990-2994. 